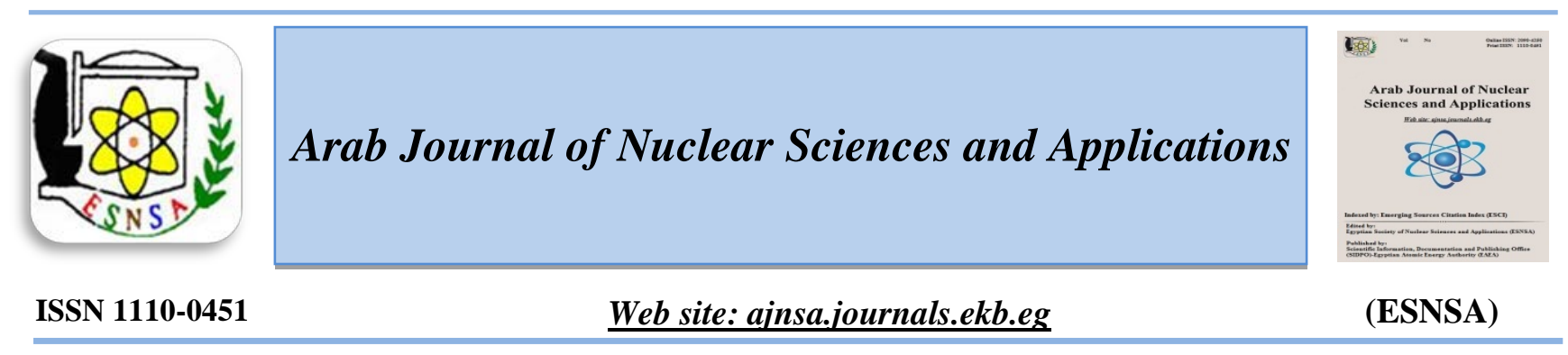

\title{
Radiation Synthesis of Novel Hydrogel Based on Wheat flour for Dyes Removal
}

\author{
E. E. Khozemy, E. M. El-Nesr, G. A. Mahmoud \\ Polymer chemistry department, National Center for Radiation Research and Technology, Egyptian Atomic Energy \\ Authority, P.O. Box 29, Nasr City, Cairo, Egypt.
}

Received $28^{\text {th }}$ Oct. 2019 A novel hydrogel based on wheat flour (F) and acrylic acid (AAc) was performed by gamma irradiation. Accepted $15^{\text {th }}$ March The parameters that controlled the preparation conditions were studied including irradiation dose and

hydrogel composition. Characterization of the produced hydrogel (F/AAc) was done by infrared spectroscopy to confirm the structure and the change in morphology was investigated by the scanning electron microscope. The thermal stability was also investigated using thermogravimetric analysis (TGA). The swelling properties were investigated in relation to time and irradiation dose. The developed hydrogel was used for the removal of Congo Red dye (CR) from aqueous solution. Effects of different operating parameters such as effect of $\mathrm{pH}$, contact time, concentration of the dye and temperature on the adsorption capacity of the dye have been studied. It was found that marvelous adsorption capacities were obtained at $\mathrm{pH} 3$. The adsorption capacity at $\mathrm{pH} 3$ is $19.5 \mathrm{mg} / \mathrm{g}$ for (F/AAc) hydrogel contains (15wt\% AAc) at $2.5 \mathrm{kGy}, 17.3 \mathrm{mg} / \mathrm{g}$ for (F/AAc) hydrogel contains (15wt\% AAc) at $20 \mathrm{kGy}$, and 13.4 $\mathrm{mg} / \mathrm{g}$ for (F/AAc) hydrogel contains (20 wt\% AAc) at $20 \mathrm{kGy}$. The pseudo-second-order model and the Freundlich model describe well the adsorption kinetic and isotherm, respectively.

\section{Introduction}

Key words: Wheat Flour/Acrylic Acid/ gamma radiation/ dye removal/ natural polymer

Toxic industrial dyes are organic compounds that produce colors to their substrates and consume a huge amount of water leading to generating an equally toxic quantity of dye-rich effluents [1].Every year, about $7 \times 10^{5}$ tons of more than 100000 various dyes are commercially produced for industrial use [2]. The textile industry uses dyes to color the products, and it produces strong color wastewater. In the dyeing processes, about $50 \%$ of the dye is lost in the wastewater due to the low level of dye-fiber fixation [3]. Therefore, it must be treated for the preservation of public health. Although the earth's surface is covered with water, many people suffer from a lack of usable water because fresh drinking water is a small amount about $1 \%$ of the amount of water on the surface of the globe. The increments in the world's population and use of chemicals have resulted in threatening the environment on Earth due to the emission of wastes and pollutants in the environment [4].

Waste water treatment is the process to make a water-worthy for a specific end-use, which may be drinking or other industrial water supply. The treatment process includes the elimination of undesirable chemicals, biological contaminants, suspended solids and pollution from wastewater. Strategies of treatment include physical methods such as sediment filtration, biological methods using a wide range of microorganisms, and chemical methods such as chlorination and the use of adsorbents [5-8]. Various waste water treatment methods, including adsorption, physical and chemical techniques have been developed for the removal of dye molecules. Among these physical and chemical methods, adsorption is considered to

Corresponding author: ehabncrrt2298@yahoo.com

DOI: 10.21608 /ajnsa.2020.18778.1289

(C) Scientific Information, Documentation and Publishing Office (SIDPO)-EAEA 
be the most promising technique because it is simple, quick, low cost and effective[9].The adsorption process has been favored for wastewater treatment because of suitability, ease of operation and the simplicity of design[1013].Additionally, adsorption is cheapness and the high-quality of the treated effluents especially for well-designed sorption processes. Adsorption has been proved as an efficient removal process for a multiplicity of solutes $[14,15]$.

Many efforts have been made to find low-cost adsorbents that have greater adsorption capacities and to be eco-friendly with the environment [16]. Therefore, some studies tested the natural materials to find inexpensive and easily available adsorbents [17-20]. The utilization of agricultural materials as an adsorbent in the removal of pollutants from waste water is great significance and has strong effects in removing of many types of pollutants such specially phenols, gasses and dyes[21,22].

Wheat flour is an important cheap renewable raw material. The major components of wheat flour are starch and proteins [23]. Starch represents about $67-68 \%$ of the whole-wheat grain [24]. Despite the fact that starch is broadly used as hydrogel-based materials, a limited use of flour is considered for this purpose. Flour is applied in the production of edible films employed in food packaging [2527].Flour, as a safe natural polymer, is used in biomedical applications such as wound dressing [28]. On the other hand, it is well known that flour is rich in functionalized groups. It contains amino acids and hydroxyl groups, which make it very effective in wastewater treatment. Besides, it has a good ability to gelatinization.

Wheat flour is not simple chemical structure, but it is a blend of many assorted starches, proteins fibers and traces of amino acids. Therefore, it has no individual chemical formula. Therefore, when dealing with wheat flour, it should be taken into account that it is composed of a mixture of several compounds that are usually bonded together by hydrogen bonds. It is well known that starch is the major component of flour. Gelatiniztion is the important step in wheat flour utilization by spacing of forces acting on bonding in starch molecules in the presence of water, plasticizers and heat [29]. Three main processes occur during gelatinization; the granule swelling reduces the double helical structure, the amylose chains begin to dissolve to separate into an amorphous form, and the number and size of crystalline regions decrease. Perry and Donald [30] showed that, glycerol, as a plasticizer, can completely gelatinize starch. The second main component of flour is protein, which is composed of amino acids sub-units linked by a peptide bond. The amino acids contain amine group, carboxylic acid group and a side-chain that varies between different amino acids. Protein also does not dissolve in water so hydrolysis should occur to accept water permeability. Hydrolysis can be catalyzed by alkaline materials such as sodium hydroxide. So they can be depolymerized, by hydrolysis producing small peptides and amino acids in the form of their sodium or potassium salt [31,32].

Preparation of copolymer resins or hydrogels is a suitable way to give desirable properties not usually observed in homopolymers [29]. In this study, acrylic acid is polymerized with wheat flour using the gamma radiation technique as a green method to perform (F/AAc) hydrogel. It is used as a strong adsorbing material for the removal of Congo Red dye based on the effectiveness of the active sites present in both wheat flour and acrylic acid. Congo Red dye Congo red is an organic compound, the sodium salt of benzidinediazo-bis1-naphtylamine-4-sulfonic acid, is a highly watersoluble benzidine-based anionic azo dye, yielding a red colloidal solution; its solubility is greater in organic solvents.

\section{Materials and Methods \\ Materials}

Wheat flour was obtained from the local market in Egypt. Acrylic acid (AAc) monomer- purity 99\% from (Sigma - Aldrich, USA) and was used as received. Other chemicals such as CR dye are of analytical reagent grade and used without further purification. The chemical structure of $\mathrm{CR}$ is shown in Fig. (1)[33].

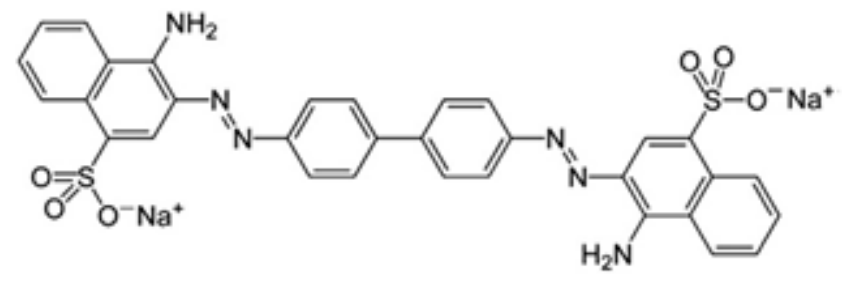

Fig. (1): chemical structure of Congo Red (CR) Preparation of (F/AAC) hydrogel 
The procedure developed for hydrogel preparation is described as follows; a solution of $4 \mathrm{wt} \%$ wheat flour was homogenized in a mixer at $\mathrm{pH} 10.7$ for 2 $\mathrm{h}$ at room temperature [25].The temperature of the solution is raised at $70{ }^{\circ} \mathrm{C}$ with stirring for 20 minutes. A plasticizer such as glycerol was added, about (20 wt\% of flour content) and continuously heated at $80{ }^{\circ} \mathrm{C}$ until the gelatinization occurred $[17,28,34]$.After that, the homogenous gel is left to cool at room temperature then various amounts of AAc monomer were added (0- 20 wt \%) and continuously stirred at room temperature for $5 \mathrm{~min}$. The prepared mixtures were poured into glass tubes and subjected to $\mathrm{Co}^{60}$ gamma irradiation, at dose rate of $1.4 \mathrm{kGy} / \mathrm{h}$ with different irradiation doses (1-25 kGy). After irradiation, the crosslinked (F/AAc) hydrogel produced was cleaned by washing in excess hot water so that un-reacted chemicals were leached out, and then dried at 40 ${ }^{\circ} \mathrm{C}$.

The crosslinked hydrogel parts were determined as follows:

The dried samples of the prepared hydrogel were soaked in distilled water for $24 \mathrm{~h}$ at $\quad 70{ }^{\circ} \mathrm{C}$. Then dried to a constant weight. The gel content was calculated by applying the following formula:

Gel content $(\%)=\frac{\mathrm{W}_{\mathrm{d}}}{\mathrm{W}_{0}} \mathrm{X} 100$

Where $\mathrm{W}_{\mathrm{d}}$ and $\mathrm{W}_{0}$ are the weights of dried samples after and before soaking in distilled water, respectively.

\section{The swelling measurements}

A sample of the dried polymer is dipped in distilled water at different time intervals and weighed again with the absorbed water after removal of the water on the surface using filter paper and the swelling percentage is calculated as follows:

Swelling (\%) $=\frac{\mathrm{W}_{\mathrm{s}}-\mathrm{W}_{\mathrm{d}}}{\mathrm{W}_{\mathrm{d}}} \times 100$

where $\mathrm{W}_{\mathrm{d}}$ and $\mathrm{W}_{\mathrm{s}}$ are the weights of the dry and the swelled hydrogel, respectively.

The effect of $\mathrm{pH}$ on the swelling behavior was allowed by immersing the samples at different $\mathrm{pH}$ solutions at room temperature.

The $\mathrm{pH}$ values were adjusted by using $0.1 \mathrm{M}$ $\mathrm{NaOH}$ or $0.1 \mathrm{M} \mathrm{HCl}$ solutions. The swelling percentage was calculated as mentioned above. Characterization of (F/AAc) hydrogel
Infrared spectroscopy FTIR of the produced hydrogel was recorded over the range of $400-4000$ $\mathrm{cm}^{-1}$, on Bruker, Unicom infra-red spectrophotometer, Germany.

Morphology of the prepared hydrogel was investigated using the scanning electron microscopy model JEOL-JSM- 5400, Tokyo, Japan. Before the examination, the samples were dried, coated with sputtered gold, observed and photographed.

Thermogravimetric analysis of the hydrogel was carried out using Shimadzu, Japan; TGA system of type TGA-50 at heating rate of $(20 \mathrm{oC} / \mathrm{min})$. The temperature ranged from ambient to $600{ }^{\circ} \mathrm{C}$. The experiments were performed under $20 \mathrm{~mL} / \mathrm{min}$ nitrogen flow.

\section{Adsorption study of (F/AAc) hydrogel}

Sorption tests of (F/AAc) hydrogel were carried out in the batch system. Batch adsorption system was conducted at different temperatures ranged between 20 and $60^{\circ} \mathrm{C}$ to obtain the data for kinetic and equilibrium parameters. Weighted dried hydrogel samples were immersed in $20 \mathrm{ml}$ of the dye solution of known initial concentration (10-50 $\mathrm{mg} / \mathrm{L}$ ) at adjusted $\mathrm{pH}$ with continuously shaken at agitation speed of $250 \mathrm{rpm}$ for appropriate time intervals. The adsorption capacity $\mathrm{q}_{\mathrm{e}}(\mathrm{mg} / \mathrm{g})$ at equilibrium was calculated using the following equation:

$q_{e}=\frac{\left(\mathrm{C}_{\mathrm{i}}-\mathrm{C}_{\mathrm{e}}\right)}{\mathrm{W}} \times V$

where, $\mathrm{C}_{\mathrm{i}}$ and $\mathrm{C}_{\mathrm{e}}$ (both in $\mathrm{mg} / \mathrm{L}$ ) are the initial dye concentration and the dye concentration at equilibrium, respectively, $\mathrm{V}$ is the solution volume (L), and $\mathrm{W}$ is the weight of the hydrogel sample (g). The concentration of CR was determined by using a UV/VIS spectrometer, model UV-Analytic Jena AG, made by German was used at $\lambda_{\max }$ of 425 $\mathrm{nm}$.

\section{Results and Discussion}

The copolymerization and cross linking of flour and AAc was performed in an aqueous medium by gamma irradiation as a clean method for hydrogel preparation. Radiolysis of water produces reactive hydroxyl radicals that attack the polymer chain. The result is abstract of hydrogen therefore, the radical center transfers to the chain. On the other hand, the $\pi$ bond on AAc monomer is attacked

Arab J. Nucl. Sci. \& Applic. Vol. 53, No.2 (2020) 
under the effect of gamma irradiation as well as free radicals is formed on AAc. Recombination of these free radicals is done and new covalent bonds are formed between the Flour macroradical chains and the free radicals on AAc. Therefore, the F/AAc hydrogel is formed. The possible reaction mechanism of F/AAc preparation is shown on Fig. (2).

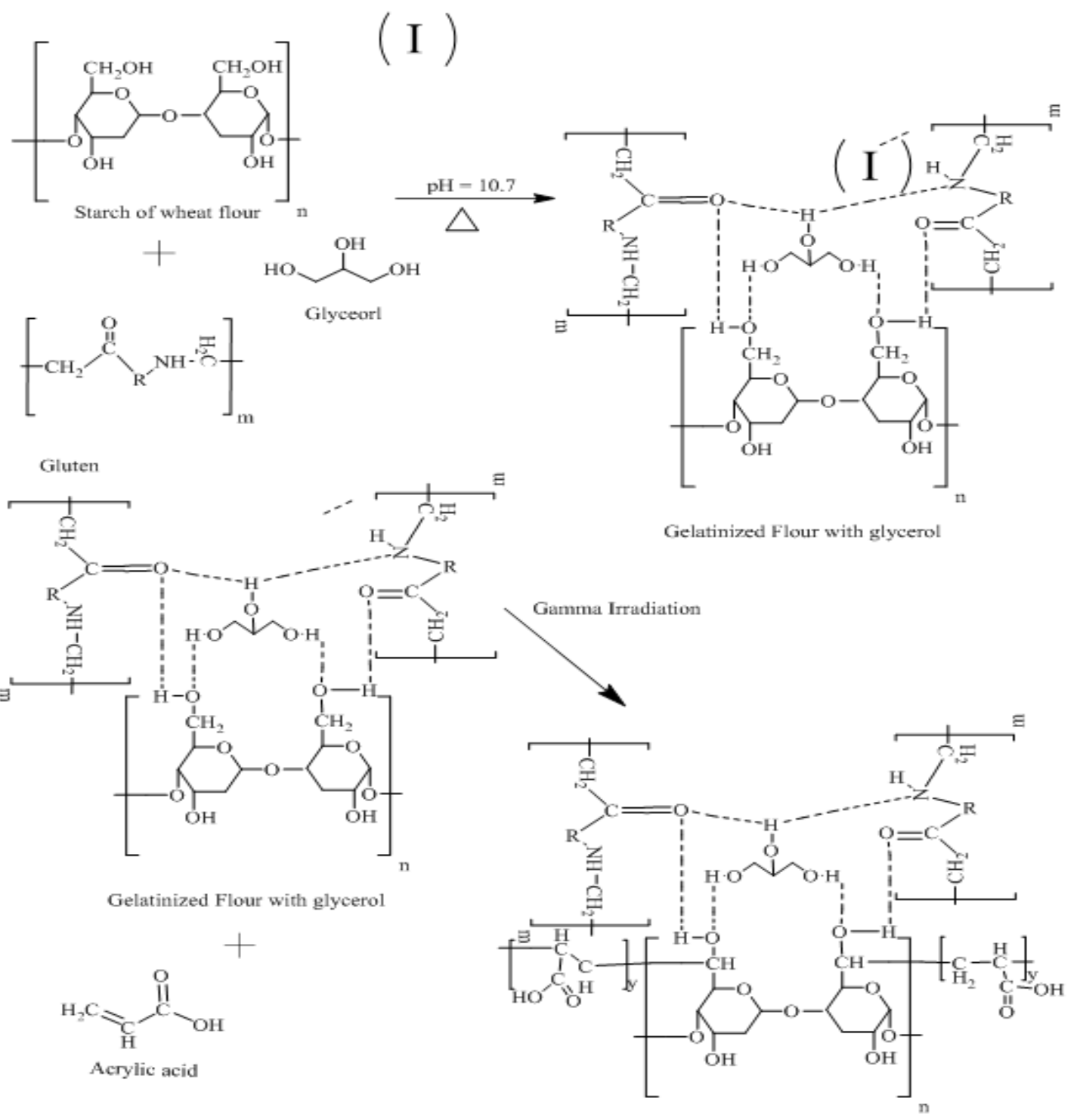

Fig. (2): The possible reaction mechanisms of wheat flour (starch and gluten) polymer chains gelatinized with glycerol and copolymerization and crosslinked with acrylic acid by gamma irradiation 
Gel content under the influence of different conditions

The gelation percentage of (F/AAc) hydrogel as a function of AAc content was shown in Fig. (3). The gel content of the hydrogel increases with increasing AAc content up to $15 \mathrm{wt} \%$, and above this value a slight decrease in gelation was obtained. As the AAc concentration increases, more radicals are formed by the effect of gamma irradiation. The radicals on the neighboring chains become close together, lead to improving the crosslinks and the gelation percentage. The increase of AAc content during the copolymerization reaction favors the propagation of chains, as well as higher gelation, is obtained [35]. However, at higher AAc content than 15 $\mathrm{wt} \%$, the radials prefer recombination as homopolymer by the viscosity effect so a decrease in the gelation percentage is obtained. It can be summarized that the optimum content of AAc in the (F/AAc) hydrogel is $15 \mathrm{wt} \%$ of the total copolymer concentration.

The effect of irradiation dose on the gelation percentage of (F/AAc) hydrogel is illustrated in Figure (4). It is observed that acceptable gelation was performed at a low irradiation dose where $80 \%$ of gelation was obtained at $1 \mathrm{kGy}$. This means a high ability of flour to combine with AAc monomer at low doses. The increase in irradiation dose, to be $2.5 \mathrm{kGy}$, enhances the crosslinking and the gelation percentage, 93\%. This irradiation dose is enough for the formation of a highly crosslinked hydrogel. Above this value, the gelation percentage is almost constant.

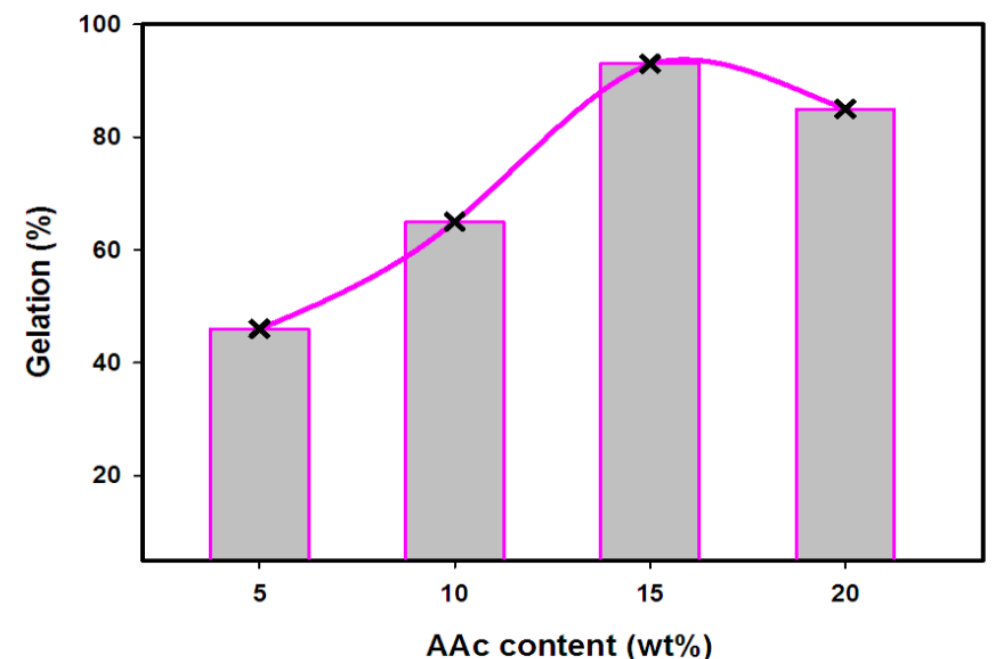

Fig. (3): Effect of monomer (AAC) content on the gelation percentage of (F/AAc) hydrogel at irradiation dose $2.5 \mathrm{kGy}$

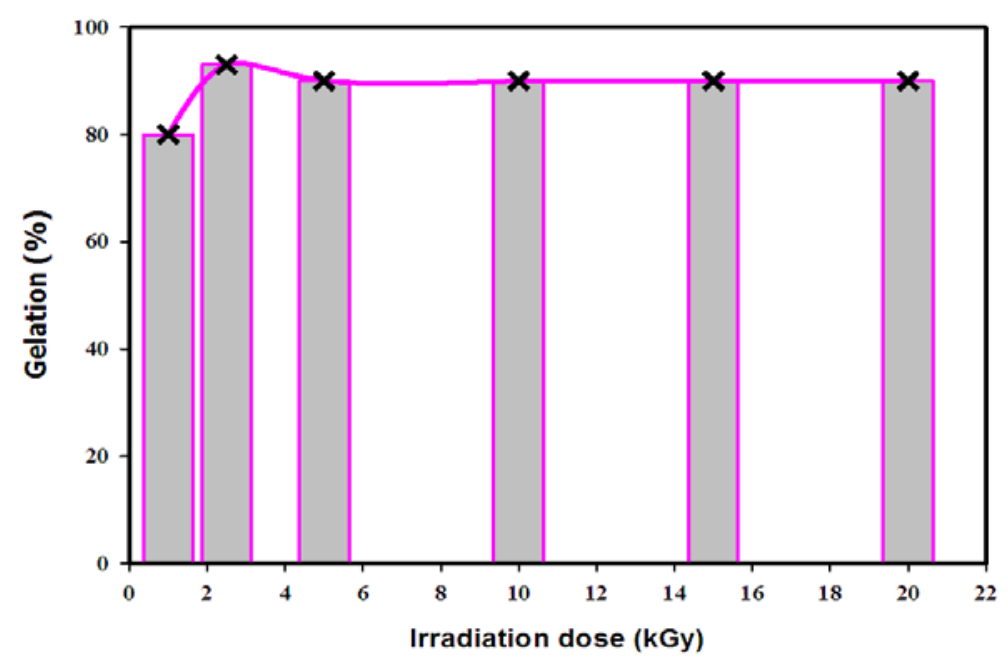

Fig. (4): Effect of Irradiation dose on the gelation percentage for (F/AAc) hydrogel at $15 \mathrm{wt} \%$ AAc of the total copolymer concentration 


\section{Swelling behavior}

The effect of swelling time on the swelling percentage of (F/AAc) hydrogel at different irradiation doses is shown in Figure (5). From this Figure, the swelling of the hydrogel increases with time until the equilibrium state is achieved after 6 h. As seen in fig.(5), the swelling percentage increases up to an irradiation dose of $10 \mathrm{kGy}$ then a decrease in swelling was observed with further increase in the irradiation dose due to the increment in the crosslinking and hence a decrease in the swelling percentage is obtained.

\section{Thermal Gravimetric Analysis}

TGA decomposition curves of $F$ and (F/AAc) hydrogels containing 15\% AAc and 20\% AAc of the total copolymer concentration is shown in Figure (6). From this Figure, three characteristic stages of polymer decomposition can be observed, the first decomposition stage within the temperature range of $29-130^{\circ} \mathrm{C}$ is attributed to the evaporation of environmentally absorbed water. The second degradation stage is between 130$400^{\circ} \mathrm{C}$ due to the degradation of the intermolecular side chains. The main weight loss occurs in the third stage within the range of $400-475^{\circ} \mathrm{C}$ which may be attributed to the decomposition of the backbone polymer. The better thermal stability is observed in (F/AAc) hydrogel due to aldehyde group in all stages of decomposition as compared to wheat flour (F) only. The interactions of the amino acid group in the polysaccharide and aldehyde groups causing high thermal stability to the blends. A small change in the thermal stability was observed by raising the AAc content in the hydrogel. It could be concluded that prepared hydrogel (F/AAc) is stable up to the temperature of $200{ }^{\circ} \mathrm{C}$, which is suitable for wastewater treatment.

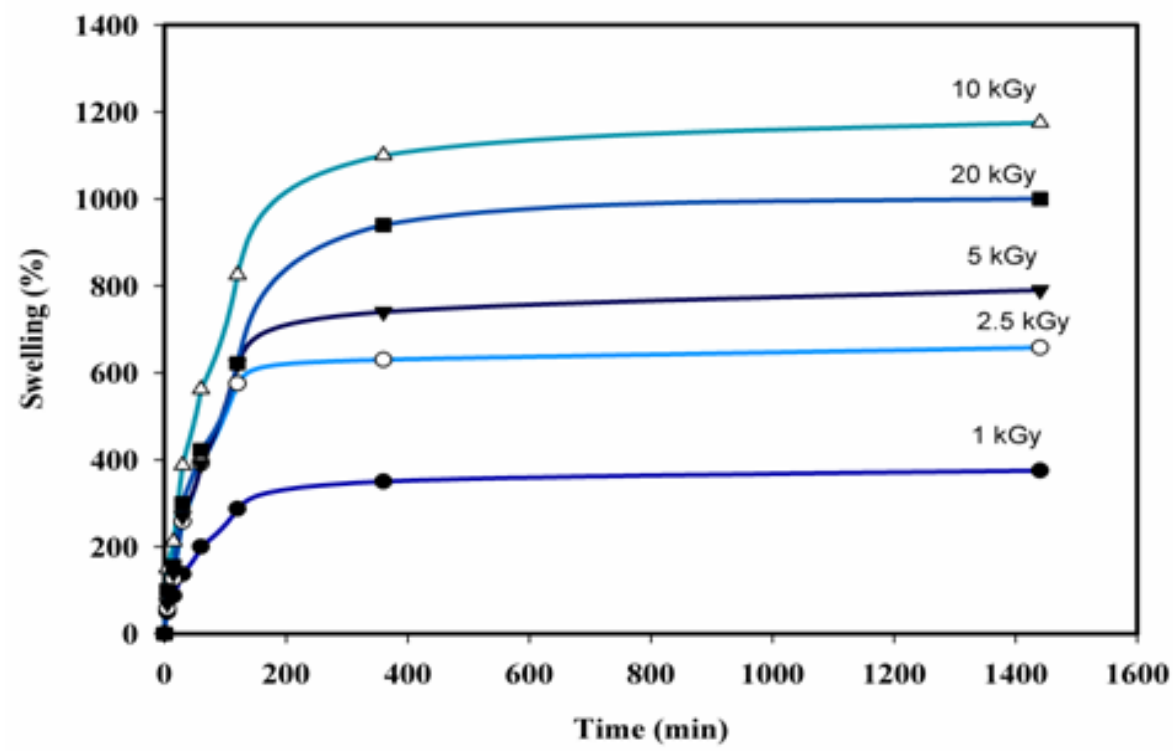

Fig. (5): Effect of time on the swelling percentage in water of (F/AAc) hydrogel at different irradiation doses and $15 \mathrm{wt} \%$ AAc of the total copolymer concentration 


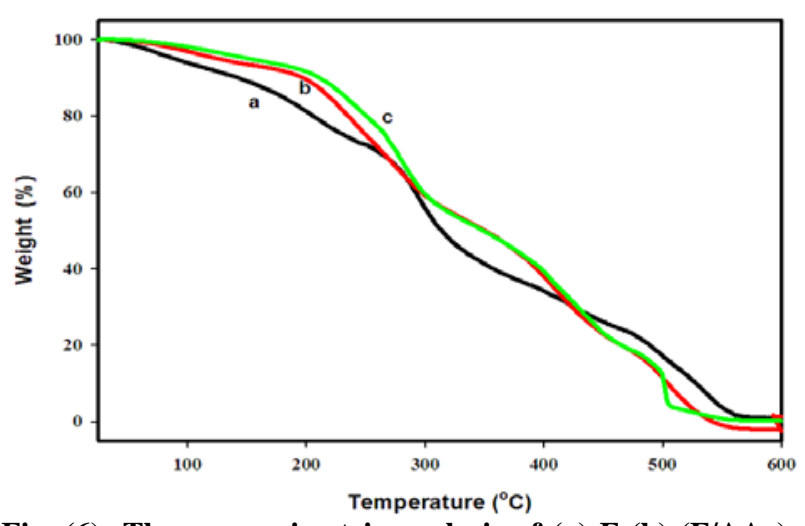

Fig. (6): Thermogravimetric analysis of (a) F (b) (F/AAc) hydrogel contains (15 wt \%) AAcand(c) (F/AAc) (20 wt \%) AAc at irradiation dose $20 \mathrm{kGy}$

\section{FTIR analysis}

Figure (7) shows the FTIR spectra of $F$ and (F/AAc) hydrogel contains $20 \mathrm{wt} \%$ of AAc of the total copolymer concentration. Considerable changes were noticed in the gelatinized $\mathrm{F}$ and $\mathrm{a}$ broad peak at $3280 \mathrm{~cm}^{-1}$ is assigned to $-\mathrm{OH}$ and NH groups. This peak becomes broad by adding AAc to the $\mathrm{F}$ in (F/AAc) hydrogel. The stretching vibration peak of $-\mathrm{CH}$ appears at $2920-2925 \mathrm{~cm}^{-1}$. The peaks at $1644 \mathrm{~cm}^{-1}$ and $1539 \mathrm{~cm}^{-1}$ are the characteristic bands of - $\mathrm{OH}$ and - $\mathrm{NH}$ bending, respectively. The peak at $1717 \mathrm{~cm}^{-1}$ corresponds to the carbonyl group in F. This peak becomes sharper in (F/AAc) hydrogel but it shifted to 1709 $\mathrm{cm}^{-1}$ due to the interactions between the primary amide $-\mathrm{NH}$ in $\mathrm{F}$ and $-\mathrm{C}=\mathrm{O}$ of AAc. The peaks at 1268-918 $\mathrm{cm}^{-1}$ corresponding to $\mathrm{C}-\mathrm{O}-\mathrm{C}$ in the glucose unit ring of starch flour. The strong peaks observed at 1269-1239 $\mathrm{cm}^{-1}$ assigned to C-O stretching vibration of the glycosidic bond. The bands at 1089 and $1030 \mathrm{~cm}^{-1}$ corresponding to $-\mathrm{CH}$ bending and $\mathrm{C}-\mathrm{O} / \mathrm{C}-\mathrm{C}$ stretching vibration, respectively. The peak at $918 \mathrm{~cm}^{-1}$ is the characteristic peak of $\mathrm{C}-\mathrm{OH}$ bending vibration. The band at $848 \mathrm{~cm}^{-1}$ is characteristic of $\mathrm{C}-\mathrm{H}$ bending [32].

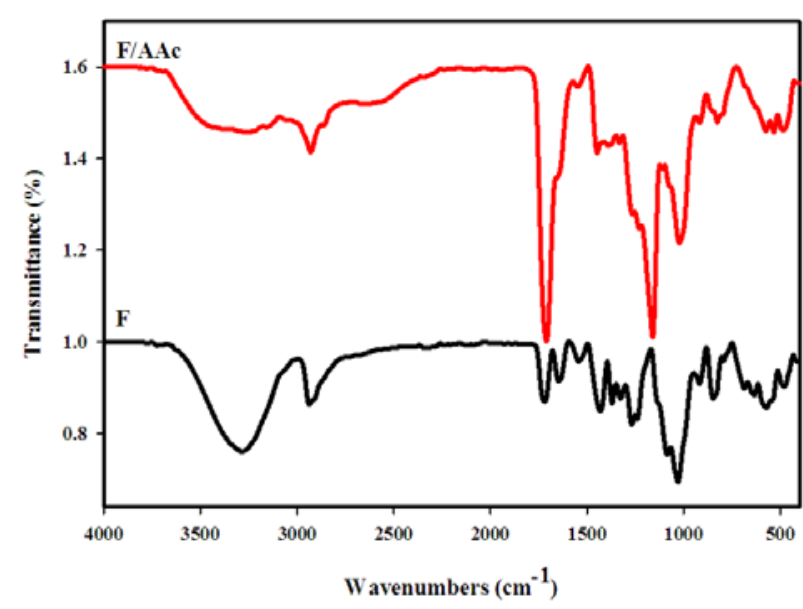

Fig. (7): FTIR spectra of $F$ and (F/AAc) hydrogel of 20 wt $\%$ AAc content of the total copolymer concentration at radiation dose $20 \mathrm{kGy}$

\section{Scanning Electron Microscopy (SEM)}

Scanning electron micrographs of Pristine Flour (F) and (F/AAc) hydrogel are shown in Fig. (8). The Figure demonstrates that the surface of $F$ appears as a coarse surface (Fig. 8a). The surface is turned to a fibrous web structure by introducing AAc into $F$ in (F/AAc) hydrogel matrix, as represented in (Fig. 8 b). It can be also noted that the density of the fibrous web structure is enhanced by increasing the irradiation dose (Fig. 8 c). The heterogenous surface of pristine flour converted by grafting of acrylic acid using irradiation techniques into a fibrous net-like structure and that increases with irradiation dose that is due to the crosslinking of the hydrogel. 


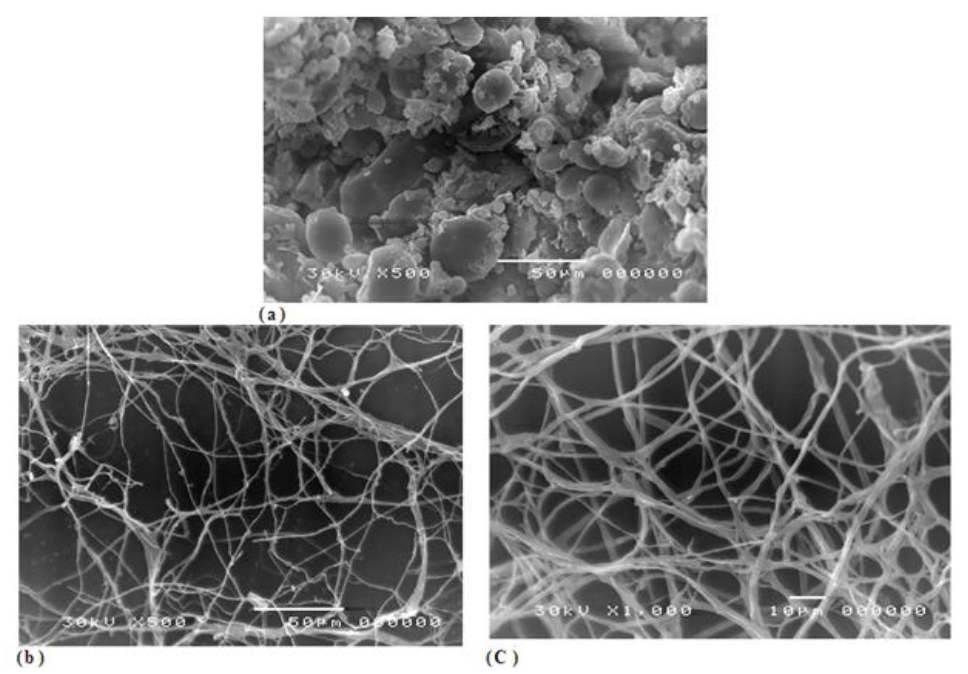

Fig. (8): SEM images of the(a) F, (b) (F / AAc 15\%) hydrogel at $2.5 \mathrm{kGy}$ and (c) at $20 \mathrm{kGy}$

\section{Adsorption study Effect of $p H$}

The effect of $\mathrm{pH}$ on the adsorption of congo red dye (CR) by (F/AAc) hydrogels under different conditions was investigated as shown in Fig. (9). It was found that the increase in $\mathrm{pH}$ value of the $\mathrm{CR}$ solution increases the adsorption capacity for all investigated (F/AAc) hydrogels. The maximum adsorption occurs at $\mathrm{pH} 3$ where the adsorption capacity is $19.5 \mathrm{mg} / \mathrm{g}$ for (F/AAc) hydrogel contains (15wt\% AAc) at $2.5 \mathrm{kGy}, 17.3 \mathrm{mg} / \mathrm{g}$ for (F/AAc) hydrogel contains (15wt\% AAc) at 20 $\mathrm{kGy}$, and $13.4 \mathrm{mg} / \mathrm{g}$ for (F/AAc) hydrogel contains (20 wt\% AAc) at $20 \mathrm{kGy}$. It is well known that CR is anionic dye contains two sulfonic groups. It is easily ionized in acidic medium to $\mathrm{CR}$ anion. As the $\mathrm{pH}$ increases, deprotonation of the carboxylic acid groups takes place. The electrostatic repulsion between the negative charges on CR anion and the negative charges on the adsorbent surface decreases the adsorption capacity. The adsorption capacity of (F/AAc) hydrogel contains (15wt\% $\mathrm{AAc}$ ) at $2.5 \mathrm{kGy}$ is the highest one followed by (F/AAc) hydrogel contains (15wt\% AAc) at 20 $\mathrm{kGy}$ and the lowest one is (F/AAc) hydrogel contains (20 wt\% AAc) at $20 \mathrm{kGy}$. (F/AAc) hydrogel contains (15wt\% AAc) at $2.5 \mathrm{kGy}$ has the highest gel content and hence, it has more active groups available for adsorption. The possible reaction mechanism for adsorption of CR dye by (F/AAc) hydrogel is shown in Fig.(10)

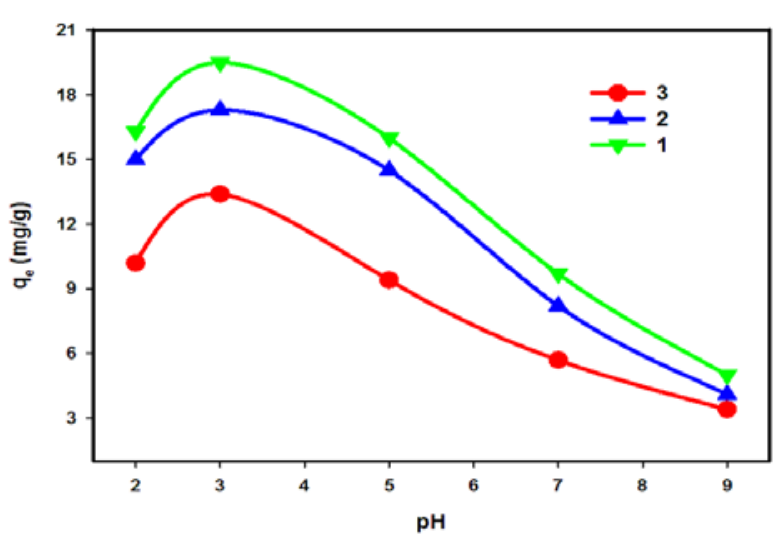

Fig. (9): Effect of pH on the adsorption capacity of (F/AAc) hydrogel (1) (15wt\% AAc) at $2.5 \mathrm{kGy}$, (2) (15wt\% AAc) at $20 \mathrm{kGy}$, and (3) (20wt\% AAc) at 20kGy 


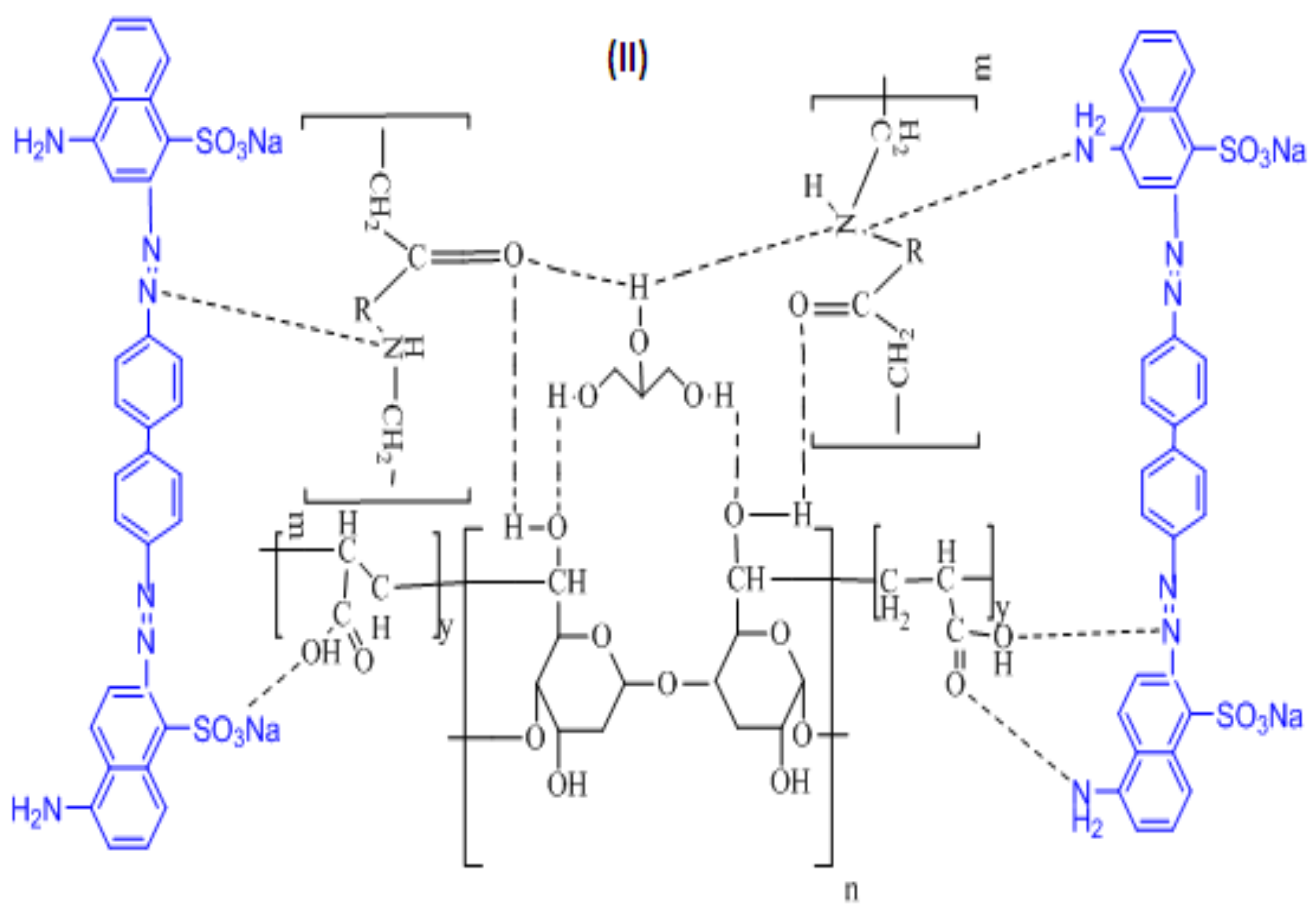

Fig. (10): The possible reaction mechanism for adsorption of CR dye onto (F/AAc) hydrogel

\section{Effect of contact time}

Effect of contact time on sorption of CR by (F/AAc) hydrogels at different monomer concentration and different irradiation doses has been investigated as shown in Fig.(11). A gradual increase in the adsorption capacity values with increasing time was observed until it reaches the maximum adsorption after $130 \mathrm{~min}$. The vacant active sites on the (F/AAc) hydrogel are available to adsorb CR. A gradual occupancy of these sites is done with time by CR dye until the complete saturation of the hydrogel surface is done [36].

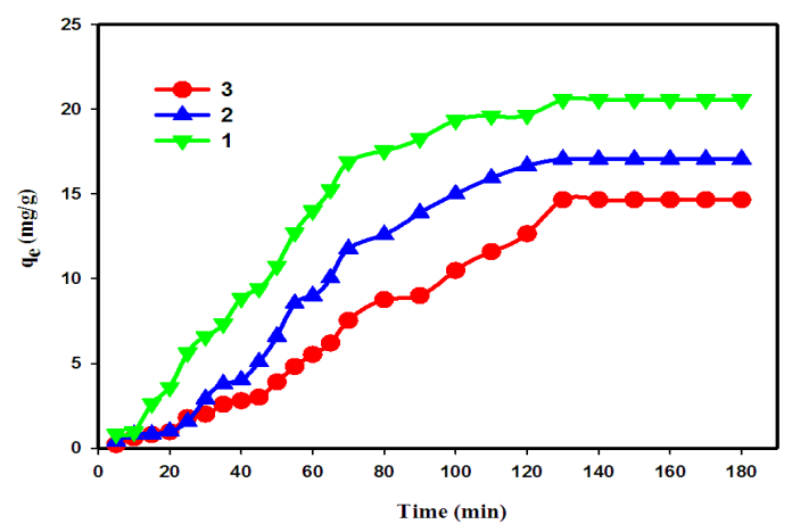

Fig. (11) Effect of time on the adsorption capacity of (F/AAc) hydrogel (1) (15wt\% AAc) at $2.5 \mathrm{kGy}$, (2) (15wt \% AAc) at $20 \mathrm{kGy}$, and (3) (20wt\% AAc) at $20 \mathrm{kGy}$

\section{Adsorption kinetics}

Pseudo-first-order and the pseudo-second-order kinetic equations are used to analyze the experimental kinetic data and toprophesy the controlling mechanism of the adsorption process.

The linear shape of the pseudo-first-order pattern is explained as the following [37].

$\log \left(q_{e}-q_{t}\right)=\log q_{e}-\frac{k_{1}}{2.303} t(4)$

$q_{e}(\mathrm{mg} / \mathrm{g})$ is the sorption capacity at equilibrium and $q_{t}(\mathrm{mg} / \mathrm{g})$ is the sorption capacity at time $\mathrm{t}$, $(\mathrm{mg} / \mathrm{g}) . k_{1}(1 / \mathrm{min})$ is the rate constant of pseudo first-order adsorption.

The pseudo-second-order kinetic pattern is demonstrated by the following linear equation [38].

$\frac{t}{q_{t}}=\frac{1}{k_{2} q_{e}^{2}}+\frac{1}{q_{e}} t$

Where $k_{2}(1 / \mathrm{min})$ is the pseudo-second- order adsorption rate constant.

The two models were utilized in the studied adsorption systems by plotting log (qe-qt) versus $t$ for pseudo-first- order model (Eq. 4) and by plotting t/qt against $t$ of pseudo-second- order kinetic model (Eq.5) as shown in Fig. 12. The obtained data are summarized in Table 1. From these data, it can be concluded that, the correlation 
Table (1): Pseudo-first-order and Pseudo-second-order obtained data for adsorption of CR by F/AAc hydrogel (1) (15wt\% AAc) at $2.5 \mathrm{kGy},(2)(15 \mathrm{wt} \%$ AAc) at 20kGy, and (3) (20wt\% AAc) at $20 \mathrm{kGy}$.

\begin{tabular}{|c|c|c|c|c|c|c|c|}
\hline \multirow[b]{2}{*}{ Туре } & \multirow[b]{2}{*}{$\begin{array}{l}\mathrm{q}_{\mathrm{e}, \exp } \\
\mathrm{mg} / \mathrm{g}\end{array}$} & \multicolumn{3}{|c|}{ Pseudo first order } & \multicolumn{3}{|c|}{ Pseudo second order } \\
\hline & & $\begin{array}{l}\mathrm{k}_{1} \mathrm{X} 10^{-3} \\
\min ^{-1}\end{array}$ & $\begin{array}{l}\mathrm{q}_{\mathrm{e}, \mathrm{cal}}, \\
\mathrm{mg} / \mathrm{g}\end{array}$ & $\mathrm{R}^{2}$ & $\begin{array}{l}\mathrm{K}_{2} \quad \mathrm{X} 10^{-3} \\
\mathrm{~g} / \mathrm{mg} / \mathrm{min}\end{array}$ & $\begin{array}{l}\mathrm{q}_{\mathrm{e}, \mathrm{cal}} \\
\mathrm{mg} / \mathrm{g}\end{array}$ & $\mathrm{R}^{2}$ \\
\hline 1 & 20.5627 & 9.6721 & 16.3598 & 0.9067 & 3.1478 & 23.3134 & 0.9792 \\
\hline 2 & 17.0597 & 16.4325 & 21.5834 & 0.8890 & 2.2357 & 18.8243 & 0.9742 \\
\hline 3 & 14.6611 & 23.5806 & 26.7991 & 0.9228 & 1.2753 & 17.1630 & 0.9792 \\
\hline
\end{tabular}
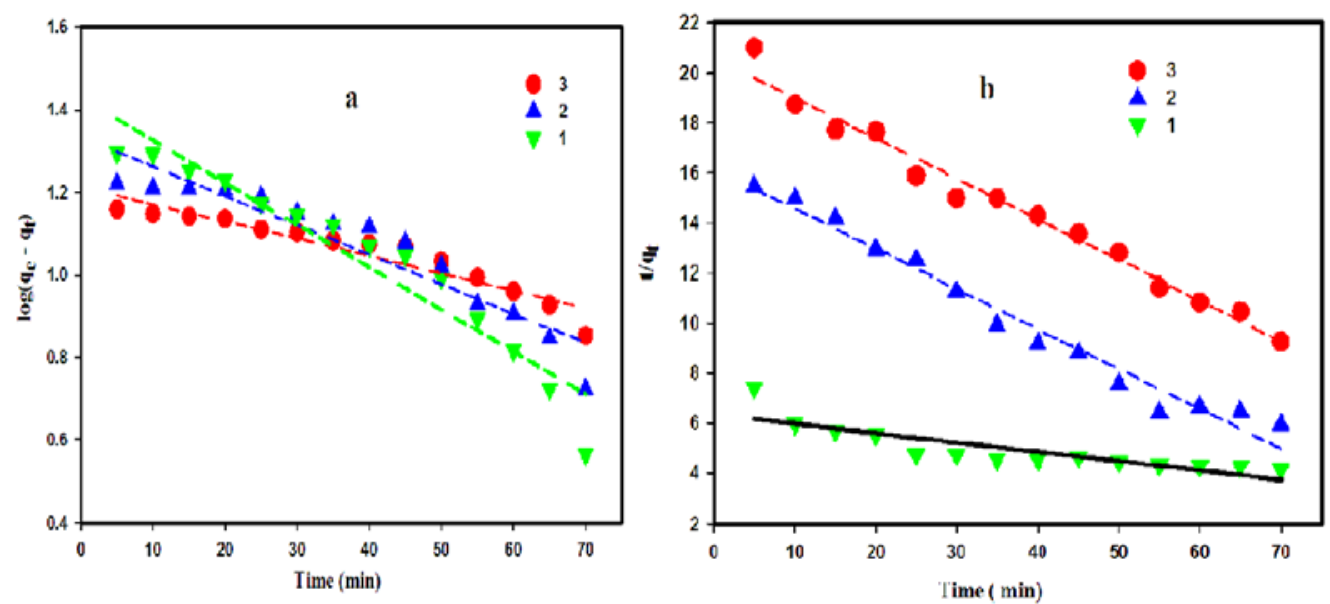

Fig. (12): Pseudo first order (a) and Pseudo second order (b) kinetic graphs for the adsorption of CR by (F/AAc) hydrogel (1) (15wt \% AAc) at $2.5 \mathrm{kGy}$, (2) (15wt\% AAc) at $20 \mathrm{kGy}$, and (3) (20wt\% AAc) at $20 \mathrm{kGy}$

coefficients $\left(\mathrm{R}^{2}\right)$ of the pseudo- second-order are higher than that of pseudo-first-order model. This means that the pseudo-second-order model describes well the adsorption of CR dye by (F/AAc) hydrogel

\section{Effect of initial concentration}

The effect of the initial dye concentration on the adsorption capacity was studied and is shown in Fig. (13). It can be found that the adsorption capacity progressively increases upon increasing the initial concentration of $\mathrm{CR}$ dye for all investigated F/AAc hydrogels. This is because of the presence of high number of CR ions in contact with accessible adsorption sites. At high initial concentration, the resistance mass transfer between the solid and aqueous phase overcomes the driving force [37].

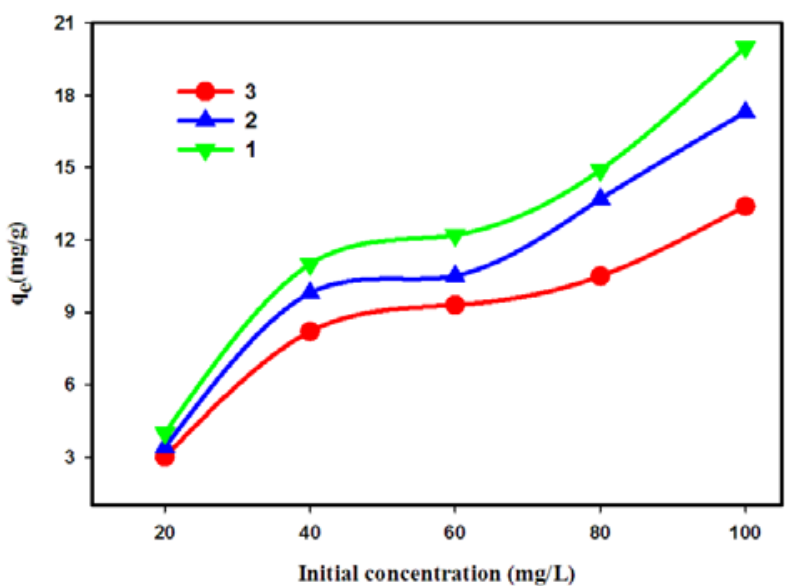

Fig. (13): Effect of initial dye concentration on the adsorption capacity of (F/AAc) hydrogel (1) (15wt\% AAc) at $2.5 \mathrm{kGy}$, (2) (15wt\% AAc) at $20 \mathrm{kGy}$, and (3) (20wt\% AAc) at $20 \mathrm{kGy}$

Adsorption isotherms

The equilibrium adsorption data were analyzed by the Langmuir and the Freundlich isotherm models. The Langmuir isotherm model (eq. 6) assumes that the intermolecular force decreases with distance. This leads to monolayer coverage of the adsorbate at specific homogeneous sites on the surface of the adsorbent. The Freundlich model (eq. 7) assumes 
that the sorbent surface is heterogeneous and the adsorption capacity is related to the concentration of adsorbate at equilibrium, where an unlimited number of sorption sites are available.

$\frac{1}{q_{e}}=\frac{1}{Q}+\frac{1}{Q b} \frac{1}{C e}$

$\ln q_{e}=\ln Q_{F}+\frac{1}{n} \ln C_{e}$

Where $C_{\mathrm{e}}(\mathrm{mg} / \mathrm{L})$ is the concentration of adsorbate in the solution at equilibrium, $q_{\mathrm{e}}(\mathrm{mg} / \mathrm{g})$ is the adsorption capacity, $\mathrm{b}$ is the Langmuir constant $(\mathrm{L} / \mathrm{mg})$ that relates to the affinity of binding sites and $\mathrm{Q}$ is the theoretical saturation capacity of the monolayer $(\mathrm{mg} / \mathrm{g}) . \quad Q_{\mathrm{F}}(\mathrm{L} / \mathrm{g})$ is the Freundlich constant, and $1 / n$ is the heterogeneity factor.

Figure (14) shows the two isotherm models plots and the isotherm model parameters are summarized in Table (2). It can be noticed from the correlation coefficient values $\left(\mathrm{R}^{2}\right)$ that the Freundlich model provided better linearity than the
Langmuir model. This means that there is an existing energetically heterogeneous site onto which multilayer adsorption takes place. The relatively high values of the correlation coefficients $\left(R^{2}\right)$ obtained from the Freundlich isotherm model indicated that the adsorption process is heterogeneous adsorption. It can be also noted that the heterogeneity factor $1 / n$ is less than unity indicated favorable adsorption.

\section{Effects of temperature}

The effect of temperature on the adsorption of CR by F/AAc hydrogels under different preparation conditions is shown in Figure (16) which shows that the equilibrium adsorption capacity increases with temperature. This result indicated the exothermic nature of the adsorption processes which may be due to a chemical reaction occurring between the functional groups of the adsorbent and the dye [39].
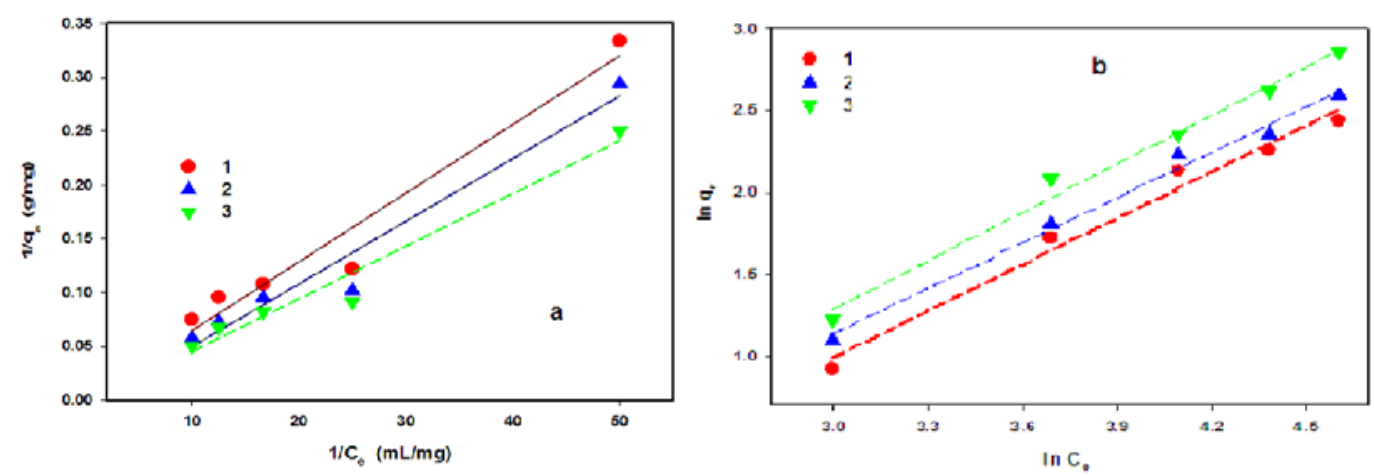

Fig. (14): Langmuir (a) and Freundlich(b) models graphs for adsorption of CR using (F/AAc) hydrogel (1) (15wt\% AAc) at $2.5 \mathrm{kGy},(2)$ (15wt \% AAc) at $20 \mathrm{kGy}$, and (3) (20wt\% AAc) at $20 \mathrm{kGy}$

Table (2): Factors of the Langmuir and Freundlich models

\begin{tabular}{ccccccc}
\hline & \multicolumn{3}{c}{ Langmuir model } & \multicolumn{3}{c}{ Freundlich model } \\
\cline { 2 - 7 } Type & $\mathrm{Q}(\mathrm{mg} / \mathrm{g})$ & $\begin{array}{c}\mathrm{b} \\
(\mathrm{L} / \mathrm{mg})\end{array}$ & $\mathrm{R}^{2}$ & $Q_{F}(\mathrm{mg} / \mathrm{g})$ & $\mathrm{n}$ & $\mathrm{R}^{2}$ \\
\hline 1 & 1.47 & 0.78 & 0.96 & 6.23 & 1.06 & 0.98 \\
2 & 1.25 & 0.80 & 0.95 & 5.06 & 1.08 & 0.99 \\
3 & 1.18 & 0.68 & 0.95 & 5.29 & 1.11 & 0.98 \\
\hline
\end{tabular}




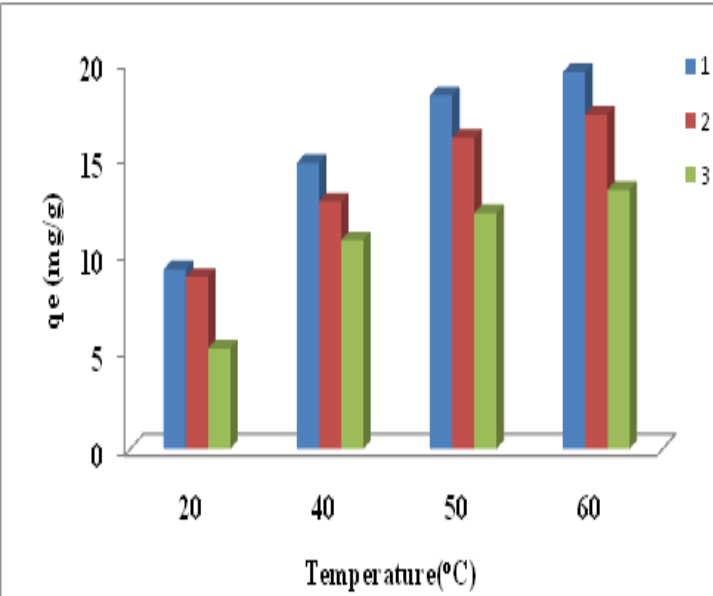

Fig. (15): Effect of temperature on the adsorption capacity of (F/AAc) hydrogel (1) (15wt\% AAc) at $2.5 \mathrm{kGy}$, (2) (15wt\% AAc) at 20kGy, and (3) (20wt\% AAc) at 20kGy

\section{Conclusions}

F/AAc hydrogel was synthesized by gammairradiation induced polymerization and crosslinking. It was observed that the gelation percentage increases with increasing AAc content up to $15 \mathrm{wt} \%$ of the total copolymer concentration. It is observed that an acceptable gelation percentage was performed at low irradiation dose where $80 \%$ of gelation is obtained at $1 \mathrm{kGy}$ and achieve to $93 \%$ at $2.5 \mathrm{kGy}$. The swelling capacity of (F/AAc) hydrogel increases with the swelling time and reaches the equilibrium state after $6 \mathrm{~h}$. The adsorption capacity of different formulations of (F/AAc) hydrogelwas studied towards CR dye. It was found that marvelous adsorption capacities were obtained at $\mathrm{pH} 3$ and the maximum adsorption capacity was obtained after $130 \mathrm{~min}$. (F/AAc) hydrogel (15wt\%AAc) at $2.5 \mathrm{kGy}$ has the highest adsorption capacity. The pseudo-secondorder model and the Freundlich model describe well the adsorption kinetic and isotherm, respectively. It was also found that the adsorption capacity increases with increasing the initial dye concentration and temperature. This result indicated the exothermic nature of the adsorption processes

\section{References}

1-Abbasian, M., Niroomand, P., and Jaymand, M. (2017) Cellulose/polyaniline derivatives nanocomposites: Synthesis and their performance in removal of anionic dyes from simulated industrial effluents. J. Appl. Polym. Sci.134, 45352

2-Banerjee, P., Barman, S. R., Mukhopadhayay, A., and Das, P. (2017) Ultrasound assisted mixed azo dye adsorption by chitosan-graphene oxide nanocomposite. Chem. Eng. Res. Des.117, 43-56

3-Adegoke, K. A., and Bello, O. S. (2015) Dye sequestration using agricultural wastes as adsorbents. Water Resour.Ind.12, 8-24

4-Vakili, M., Rafatullah, M., Gholami, Z., and Farraji, H. (2016) Treatment of reactive dyes from water and wastewater through chitosan and its derivatives. Smart Materials for Waste Water Applications, 347377

5-Kurniawan, T. A., Chan, G. Y., Lo, W.-H., and Babel, S. (2006) Physico-chemical treatment techniques for wastewater laden with heavy metals. Chem.Eng.J.118, 83-98

6-Chinoune, K., Bentaleb, K., Bouberka, Z., Nadim, A., and Maschke, U. (2016) Adsorption of reactive dyes from aqueous solution by dirty bentonite. Appl. Clay Sci.123, 64-75

7-Acar, I., Bal, A., and Güçlü, G. (2012) Adsorption of Basic Dyes from Aqueous Solutions by Depolymerization Products of Post-Consumer PET Bottles. CLEAN-Soi Air Water.40, 325-333

8-Gul, K., Sohni, S., Waqar, M., Ahmad, F., Norulaini, N. N., and AK, M. O. (2016) Functionalization of magnetic chitosan with graphene oxide for removal of cationic and anionic dyes from aqueous solution. Carbohydr.Polym.152, 520-531

9-Yan, Y., Xiang, B., Yi, X., Li, Y., and Jia, Q. (2014) Competitive adsorption of acid dyes from aqueous solution on diethylenetriamine-modified chitosan beads. J. Appl. Polym. Sci.131

10-Hegazy, D. E.-S. (2012) Selectivity of Acrylic Acid Radiation Grafted Non-Woven Polypropylene Sheets towards Some Heavy Metals Ions. OJP Chem.2, 6.

11-Mahmoud, G. A., Mohamed, S. F., and Hassan, H. M. (2015) Removal of methylene blue dye using biodegradable hydrogel and reusing in a secondary adsorption process. Desalin. water treat.54, 27652776

12-De Gisi, S., Lofrano, G., Grassi, M., and Notarnicola, M. (2016) Characteristics and adsorption capacities of low-cost sorbents for wastewater treatment: a review. Sustainable Mater. Technol.9, 10-40

13-El-Mohdy, H. A., Hegazy, E., El-Nesr, E., and ElWahab, M. (2013) Metal sorption behavior of poly (N-vinyl-2-pyrrolidone)/(acrylic acid-co-styrene) hydrogels synthesized by gamma radiation. J. Environ. Chem. Eng.1, 328-338

14-Ahamad, T., Naushad, M., Al-Maswari, B. M., Ahmed, J., ALOthman, Z. A., Alshehri, S. M., and Alqadami, A. A. (2017) Synthesis of a recyclable mesoporous nanocomposite for efficient removal of 
toxic Hg2+ from aqueous medium. J. ind.Eng.Chem.53, 268-275

15-Singh, T., and Singhal, R. (2013) Reuse of a waste adsorbent poly (AAc/AM/SH)-Cu superabsorbent hydrogel, for the potential phosphate ion removal from waste water: Matrix effects, adsorption kinetics, and thermodynamic studies. J. Appl. Polym. Sci.129, 3126-3139

16-Xie, K., Jing, L., Zhao, W., and Zhang, Y. (2011) Adsorption removal of $\mathrm{Cu} 2+$ and $\mathrm{Ni} 2+$ from waste water using nano-cellulose hybrids containing reactive polyhedral oligomeric silsesquioxanes. J. Appl. Polym. Sci.122, 2864-2868

17-Andrade-Mahecha, M. M., Tapia-Blácido, D. R., and Menegalli, F. C. (2012) Development and optimization of biodegradable films based on achira flour. Carbohyd.Polym.88, 449-458

18-Diéguez, M. C. V., Pelissari, F. M., do Amaral Sobral, P. J., and Menegalli, F. C. (2015) Effect of process conditions on the production of nanocomposite films based on amaranth flour and montmorillonite. LWT-Food Sci. Technol.61, 70-79

19-Chan, M. Y., Koay, S. C., Husseinsyah, S., and Sam, S. T. (2018) Cross-linked Chitosan/Corn Cob Biocomposite Films with Salicylaldehyde on Tensile, Thermal, and Biodegradable Properties: A Comparative Study. Adv. Polym. Technol.37, 12291239

20-Zhao, B., Xiao, W., Shang, Y., Zhu, H., and Han, R. (2017) Adsorption of light green anionic dye using cationic surfactant-modified peanut husk in batch mode. Arabian J. Chem.10, S3595-S3602

21-Salleh, M. A. M., Mahmoud, D. K., Karim, W. A. W. A., and Idris, A. (2011) Cationic and anionic dye adsorption by agricultural solid wastes: A comprehensive review. Desalination280, 1-13

22-Bello, O. S., Adegoke, K. A., Olaniyan, A. A., and Abdulazeez, H. (2015) Dye adsorption using biomass wastes and natural adsorbents: overview and future prospects. Desalin. Water Treat.53, 1292-1315

23-Chabrat, E., Abdillahi, H., Rouilly, A., and Rigal, L. (2012) Influence of citric acid and water on thermoplastic wheat flour/poly (lactic acid) blends. I: Thermal, mechanical and morphological properties. Ind. Crops Prod.37, 238-246

24-El-Porai, E., Salama, A., Sharaf, A., Hegazy, A., and Gadallah, M. (2013) Effect of different milling processes on Egyptian wheat flour properties and pan bread quality. Annals of Agricultural Sciences58, 5159

25-Tapia-Blácido, D., Sobral, P. J., and Menegalli, F. C. (2005) Development and characterization of biofilms based on Amaranth flour (Amaranthus caudatus). J. Food Eng.67, 215-223

26-Lü, J., and Ma, D. (2015) Effect of wheat flour packaging materials on infestation by Lasioderma serricorne (F.). J. Food Prot.78, 1052-1055
27-Olkku, J., and Rha, C. (1978) Gelatinisation of starch and wheat flour starch-a review. Food Chem.3, 293-317

28-Park, J.-S., Kim, H.-A., Choi, J.-B., Gwon, H.-J., Shin, Y.-M., Lim, Y.-M., Khil, M. S., and Nho, Y.-C. (2012) Effects of annealing and the addition of PEG on the PVA based hydrogel by gamma ray. Radiat. Phys. Chem.81, 857-860

29-Zobel, H. F. (1984) Gelatinization of starch and mechanical properties of starch pastes. in Starch: Food. Sci. technol. Elsevier. pp 285-309

30-Perry, P., and Donald, A. (2000) The role of plasticization in starch granule assembly. Biomacromolecules1, 424-432

31-Saikhwan, P., Mercadé-Prieto, R., Chew, Y. J., Gunasekaran, S., Paterson, W., and Wilson, D. I. (2010) Swelling and dissolution in cleaning of whey protein gels. Food Bioprod. Process.88, 375-383

32-Mercadé-Prieto, R., Chen, X. D., Falconer, R., Paterson, W., and Wilson, I. (2005) The poor perfomance of $\mathrm{NaOH}$ in the dissolution of whey protein gels and very high $\mathrm{pH}$.

33-Mahmoud, G. A., Abdel-Aal, S. E., Badway, N. A., Elbayaa, A., and Ahmed, D. F. (2017) A novel hydrogel based on agricultural waste for removal of hazardous dyes from aqueous solution and reuse process in a secondary adsorption. Polym. Bull.74, 337-358

34-34. Alver, E., Bulut, M., Metin, A. Ü., and Çiftçi, H. (2017) One step effective removal of Congo Red in chitosan nanoparticles by encapsulation. Spectrochim. Acta. Part A: Molecular and Biomolecular Spectroscopy 171, 132-138

35-Mansour, T., El-Gammal, B., Khalil, F.H., El-Nesr, E. M., Hegazy, E. A. and El- Sabbah, M. M.B. (2011) Copolymers of acrylic acid / acrylonitrile prepared by gamma irradiation and its application in radioactive waste solution treatment. J. Rad. Res. Appl. Sci., 4, .3(B), 989-1004

36-Tapia-Blácido, D., do Amaral Sobral, P., and Menegalli, F. (2011) Optimization of amaranth flour films plasticized with glycerol and sorbitol by multiresponse analysis. LWT-Food Sci. Technol.44, 17311738

37-Ho, Y.-S. (2006) Review of second-order models for adsorption systems. J. Hazard. Mater.B136 (2006) 681-689

38-MCKAY, Y. S. H. a. G. (2000) The Kinetics Of Sorption Of Divalent Metal Ions Onto Sphagnum Moss Peat. Water Res. 34, 3, 735-742.

39-Arivoli, S., Hema, M., Martin, P. D. P. (2009) Adsorption Of Malachite Green Onto Carbon Prepared From Borassus Bark. science and engineering, 34, 31-43.

Arab J. Nucl. Sci. \& Applic. Vol. 53, No.2 (2020) 